\title{
Um estudo sobre o nível de aderência de companhias do segmento químico e petroquímico às normas $e$ recomendações de disclosure ambiental internacionais, norte americanas e brasileiras
}

\begin{abstract}
Ângela Rosane Leal de Souza Mestrado em Ciências Contábeis pela Universidade do Vale do Rio dos Sinos UNISINOS

Professora do Centro Universitário Metodista Avenida Unisinos, 950. Bairro Cristo Rei. São Leopoldo/RS. CEP: 93022-000 E-mail: angela.rsl@gmail.com

Ernani Ott Doutorado em Ciências Contábeis pela Universidade de Deusto - Espanha Professor da Universidade do Vale do Rio dos Sinos - UNISINOS Avenida Unisinos, 950. Bairro Cristo Rei. São Leopoldo/RS. CEP: 93022-000 E-mail:ernani@unisinos.br

Clóvis Antônio Kronbauer Doutorado em Contabilidade e Auditoria, Universidade de Sevilha - Espanha Professor da Universidade do Vale do Rio dos Sinos - UNISINOS Avenida Unisinos, 950. Bairro Cristo Rei. São Leopoldo/RS. CEP: 93022-000

E-mail: clovisk@unisinos.br
\end{abstract}

\section{RESUMO}

O crescente interesse em âmbito mundial e a conscientização de que as organizações e os organismos governamentais devem desempenhar um papel importante na luta por um desenvolvimento sustentável, têm levado à edição de várias normas e recomendações de disclosure ambiental. Alguns organismos internacionais ligados a área contábil como o Intergovernmental Working Group of Experts on International Standards of Accounting and Reporting (ISAR/UNCTAD) têm dedicado atenção às informações contábeis relativas à sustentabilidade ambiental. Da mesma forma, nos Estados Unidos da América e no Brasil, alguns organismos têm emitido normas relacionadas ao registro contábil e à publicação de informes ambientais nos relatórios anuais das companhias. Nesse contexto, este estudo, de caráter exploratório-descritivo, avalia o nível de aderência às normas e recomendações de organismos internacionais e nacionais relativos ao disclosure ambiental, de uma amostra de 10 (dez) companhias do setor químico e petroquímico emitentes de American Depositary Receipts (ADRs), que negociam ações na New York Stock Exchange (NYSE) e que desempenham atividades no Brasil. Para atingir o objetivo proposto, fez-se uma pesquisa nos relatórios publicados pelas companhias e se procedeu a uma análise qualitativa destes relatórios. Os resultados do estudo indicam que a aderência às recomendações internacionais não atinge a 50\%, em média; se situa em torno de $70 \%$, em média, em relação às 
Um estudo sobre o nível de aderência de companhias do segmento químico e petroquímico às normas e recomendações de disclosure ambiental internacionais, norte americanas e brasileiras Ângela Rosane Leal de Souza, Ernani Ott, Clóvis Antônio Kronbauer

normativas norte-americanas; e há uma baixa aderência às recomendações emanadas dos organismos brasileiros, apenas $18 \%$.

Palavras-chave: Disclosure ambiental. Desenvolvimento sustentável. Normas e recomendações ambientais.

\section{A study on the level of compliance of chemical and petrochemical companies with the international, north American and brazilian environmental disclosure standards an recommendations}

\section{ABSTRACT}

In view of the growing worldwide interest and awareness of the fact that government organizations and authorities should have an important role in fostering sustainable development, various disclosure standards and recommendations are being issued. Some international agencies involved in the field of accountancy, such as the Intergovernmental Working Group of Experts on International Standards of Accounting and Reporting (ISAR/UNCTAD) have given attention to the accountancy information concerning environmental sustainability. Likewise, some United States and Brazilian organisms have issued standards pertaining to the accountancy entries and publication of environmental reports in annual company reports. This exploratory-descriptive study, operating in this context, seeks to evaluate the compliance of a sampling of ten (10) companies in the chemical and petrochemical sector that issue American Depositary Receipts (ADRs), and are quoted on the New York Stock Exchange (NYSE), and operate in Brazil, to the standards and recommendations of national and international agencies concerning environmental disclosure. To achieve that purpose the company documentation is surveyed and a qualitative analysis is carried out on the companies' published reports. The results of the studies show that compliance with international recommendations is lower than $50 \%$, and on the average it is about $70 \%$ as to U.S. standards and low concerning the recommendations of Brazilian agencies, less than $20 \%$.

Key Words: Environmental disclosure. Sustainable development. Environmental standards and recommendations.

\section{INTRODUÇÃO}

Nos últimos anos a sociedade vem questionando, de forma crescente, o significado do conceito de progresso e os limites toleráveis dos níveis de poluição provocada por empreendimentos industriais. Tais questionamentos, somados às 
Um estudo sobre o nível de aderência de companhias do segmento químico e petroquímico às normas e recomendações de disclosure ambiental internacionais, norte americanas e brasileiras Ângela Rosane Leal de Souza, Ernani Ott, Clóvis Antônio Kronbauer

exigências de um mercado globalizado e à preocupação com o esgotamento e o comprometimento dos recursos naturais, têm levado à criação de dispositivos reguladores na legislação ambiental em relação aos processos industriais.

Os efeitos da degradação e a poluição ambiental há alguns anos era uma preocupação restrita a um pequeno grupo de ecologistas, que procurava alertar a população mundial acerca dos danos que o modelo de desenvolvimento adotado pelas empresas poderia causar ao meio ambiente. Hoje, entretanto, já há uma conscientização de que as organizações e os órgãos governamentais devem empenhar-se para garantir a preservação do meio ambiente.

Nesse contexto, o tema meio ambiente deve ser tratado de forma multidisciplinar e a contabilidade, na sua condição de ciência social, deve incluí-lo em suas discussões, estudos e pesquisas. Por intermédio da divulgação de informações, especialmente de obrigações e contingências ambientais que afetam ou venham a afetar a posição financeira das empresas, a contabilidade também pode constituir-se em um instrumento importante de controle e proteção ambiental.

Dada a importância do tema, normas e recomendações de natureza contábil estão sendo editadas por organismos internacionais (ISAR/UNCTAD); norteamericanos (SEC; FASB; AICPA) e brasileiros (CFC; IBRACON), entre outros, relacionadas tanto com a identificação dos eventos envolvendo os ativos, passivos, custos, despesas e receitas ambientais, quanto à sua evidenciação nos relatórios anuais das companhias.

No cenário industrial, as indústrias químicas e petroquímicas estão entre as principais responsáveis pela geração de resíduos de alta periculosidade e produzem uma série de materiais sólidos e resíduos oleosos de difícil reaproveitamento em curto prazo, causando uma enorme dificuldade na destinação apropriada desses materiais. Essa condição faz com que seja relevante examinar o comportamento das empresas desse segmento no que se refere à divulgação de informações relacionadas com a temática ambiental. 
Um estudo sobre o nível de aderência de companhias do segmento químico e petroquímico às normas e recomendações de disclosure ambiental internacionais, norte americanas e brasileiras Ângela Rosane Leal de Souza, Ernani Ott, Clóvis Antônio Kronbauer

Dessa forma, estabeleceu-se como objetivo desta pesquisa: examinar o nível de aderência de empresas do setor químico e petroquímico, que emitem American Depositary Receipts (ADRs), negociam ações na New York Stock Exchange (NYSE) e mantém atividades no Brasil, às normas e recomendações de organismos internacionais, norte-americanos e nacionais, relativos à divulgação de informações de natureza ambiental.

Para atingir esse objetivo, inicialmente, descreve-os principais elementos das normas e recomendações dos citados organismos relativos ao disclosure ambiental, procedendo-se então a análise de aderência das empresas estudadas averiguando se as divulgações efetuadas atendem a tais normas e recomendações.

\section{REFERENCIAL TEÓRICO}

\subsection{Estudos sobre a temática ambiental}

No Brasil, as pesquisas relativas à temática ambiental na área contábil tiveram início com o estudo de Ribeiro (1992). Nesse estudo, a autora relaciona conceitos da contabilidade ambiental e examina a tendência de divulgação das informações ambientais pela contabilidade tanto no Brasil, quanto em nível mundial, expondo que, infelizmente, as questões ambientais só se tornaram objeto de preocupação dos empreendedores de atividades econômicas poluentes quando os níveis de poluição da água, solo e ar atingiram altos patamares. Nas considerações finais, a autora alerta para a necessidade da busca de alternativas para adequar o desenvolvimento econômico às limitações da natureza, cabendo à contabilidade empenhar-se para ser um instrumento de informação que reflita fidedignamente o valor do patrimônio das empresas, inclusive sob o aspecto ambiental.

Martins e De Luca (1994) destacam que previamente às evidenciações de informações ambientais, são necessárias metodologias adequadas de controle ambiental, partindo-se de um trabalho de conscientização dos empresários em relação à relevância da proteção ambiental, passando, então, para decisões de ordem econômica e financeira que irão gerar os fatos que deverão ser registrados e 
Um estudo sobre o nível de aderência de companhias do segmento químico e petroquímico às normas e recomendações de disclosure ambiental internacionais, norte americanas e brasileiras Ângela Rosane Leal de Souza, Ernani Ott, Clóvis Antônio Kronbauer

evidenciados. Sob esse prisma, citam-se, como exemplo, as seguintes pesquisas: Guesser e Beuren (1998) e Ribeiro (1998), que realizaram estudos relativos à identificação, mensuração e evidenciação dos custos ambientais e a importância deles na gestão estratégica de custos; os estudos de Ferreira (1998; 2003), que propõem um modelo de informações que utiliza o Sistema de Gestão Econômica (GECON) para apurar o resultado da gestão ambiental; e uma pesquisa de Andrade (2000), que ressaltou a necessidade do desenvolvimento de técnicas que permitam que os passivos ambientais sejam identificados, registrados e evidenciados.

Sob outro enfoque, um estudo de Nossa (2002) investigou o nível de disclosure de informações ambientais pelas empresas do setor de papel e celulose. Para atingir o objetivo proposto, foi desenvolvida uma análise de conteúdo dos relatórios de 42 das 50 maiores empresas desse segmento em nível mundial. Os resultados do estudo apontaram divergências entre as informações das companhias quanto: (a) ao tamanho da empresa; (b) ao país de localização; (c) ao tipo de relatório (financeiro ou específico); mostrando-se incipiente e frágil em relação ao nível de confiabilidade e comparabilidade das informações. Nas conclusões do estudo, o autor expõe que as informações são praticamente descritivas e evidenciadas em relatórios específicos. Além disso, constatou que o nível de disclosure ambiental das empresas dos outros países é mais detalhado que o das empresas brasileiras.

No âmbito da evidenciação de informações ambientais outro estudo a ser destacado é o realizado por Paiva (2003), que teve por objetivo avaliar a evidenciação de gastos ambientais nas maiores empresas do setor de papel e celulose atuantes no Brasil. Nas suas conclusões, o autor destaca a carência de evidenciação de informações ambientais por parte do setor estudado, não permitindo aos stakeholders um suficiente detalhamento que os possibilitem efetuar inferências relativas aos impactos desses gastos no desempenho futuro da organização.

Gamble et al. (1995); Burritt e Welch (1997); Stanny (1998), em suas pesquisas, constataram um crescente aumento na quantidade de informações ambientais divulgadas nos relatórios anuais das companhias examinadas. Além destes, pode-se citar vários outros estudos abordando a temática ambiental, tanto em nível nacional 
Um estudo sobre o nível de aderência de companhias do segmento químico e petroquímico às normas e recomendações de disclosure ambiental internacionais, norte americanas e brasileiras Ângela Rosane Leal de Souza, Ernani Ott, Clóvis Antônio Kronbauer

(Ribeiro, 1992; Ferreira, 1998; Nossa, 2002; Paiva, 2003; Calixto, 2004) quanto em nível internacional (Ingram; Frazier, 1980; Gray, 1994; Deegan; Ranking, 1996; Hackston; Milne, 1996; Emery, 2002; Berthelot; Cormier; Magnan, 2003). Tal fato demonstra o crescente interesse dos pesquisadores da área contábil em relação ao disclosure ambiental, visando atender as necessidades informativas de diferentes grupos de usuários.

\subsection{Evidenciação de informações ambientais}

González et al. (2002) destacam que os primeiros antecedentes das normatizações da evidenciação ambiental se encontram nas normas norte-americanas da Security and Exchange Commission (SEC) e do Financial Accounting Standards Board (FASB), sendo o Canadá o segundo país a tratar de normatização contábil dos aspectos ambientais. Em 1993, o Canadian Institute of Chartered Accountants (CICA) realizou um estudo das necessidades informativas de diferentes usuários relacionadas com o impacto ambiental das empresas. O resultado desse estudo foi publicado sob o título Environmental Costs and Liabilities: Accounting and Financial Reporting (CICA, 1993), considerado uma importante referência para a contabilidade ambiental.

$\mathrm{Na}$ Europa, também é cada vez maior o número de evidenciações das estratégias de responsabilidade ambiental, como resposta às diversas pressões da sociedade européia relativo a essa temática. A Fédération des Experts Comptables Européens (FEE) e a Comisión de Las Comunidades Europeas são organismos atuantes no âmbito da União Européia que têm emitido pareceres sobre a contabilização e evidenciação de eventos ambientais (FEE, 2006).

$\mathrm{Na}$ Espanha, desde 1988, as normatizações relativas à matéria ambiental são emitidas pelo Instituto de Contabilidad y Auditoría de Cuentas (ICAC), um organismo autônomo, vinculado ao Ministério de Economia e Fazenda da Espanha. Em 2002, a Resolução no 6.389, emitida pelo ICAC, torna obrigatória a evidenciação das informações de natureza ambiental nas contas anuais das médias e grandes empresas do país (ICAC, 2002). Esse estímulo à divulgação de informações e à regulamentação do disclosure ambiental também pode ser observado em Portugal. Nesse país, foi 
Um estudo sobre o nível de aderência de companhias do segmento químico e petroquímico às normas e recomendações de disclosure ambiental internacionais, norte americanas e brasileiras Ângela Rosane Leal de Souza, Ernani Ott, Clóvis Antônio Kronbauer

editada em 5 de dezembro de 2005 a Directriz Contabilística (DC) ‥ 29 - Matérias Ambientais, estabelecendo que as empresas portuguesas deverão prestar informações relativas à matéria ambiental nas demonstrações financeiras anuais (PORTUGAL, 2005).

Em outros países também se observa uma crescente preocupação com a evidenciação de informações de natureza ambiental. Uma regra introduzida no disclosure ambiental no Japão, por exemplo, requer que as companhias informem os riscos materiais ambientais que poderão causar à descontinuidade da empresa. De acordo com Kawamura (apud Chan-Fishel, 2003, p. 5),

as regras novas exigem não só informações financeiras diretas, mas incluem também a provável deterioração de imagem da marca da companhia. Isto porque se a impropriedade de uma companhia afeta seu Corporate Social Responsibility (CSR), esta enfrenta o risco não só de sanções legais, mas de sanções do mercado e da sociedade; quer dizer, de uma reação adversa dos parceiros empresariais e consumidores (tradução livre).

\subsection{Normas e recomendações de evidenciações ambientais do ISAR/UNCTAD}

O Intergovernmental Working Group of Experts on International Standards of Accounting and Reporting (ISAR) é um grupo de trabalho que reúne especialistas em contabilidade para realizar estudos no sentido de estabelecer a padronização das práticas contábeis no nível corporativo. O seu objetivo é primar pela transparência nas informações econômico-financeiras divulgadas pelas empresas, característica considerada como um elemento essencial para orientar o processo de tomada de decisões dos diversos interessados nas informações contábeis (ISAR/UNCTAD, 2005).

Para o ISAR/UNCTAD, as organizações de grande ou pequeno porte devem evidenciar em seus relatórios financeiros anuais as informações relativas às suas atividades econômicas que afetam o meio ambiente. Desta forma, com o objetivo de promover a adoção das melhores práticas de divulgação de informações ambientais, dedicou grande atenção à contabilidade ambiental no sentido de determinar diretrizes metodológicas mais apropriadas ao disclosure ambiental. Um trabalho disponibilizado 
Um estudo sobre o nível de aderência de companhias do segmento químico e petroquímico às normas e recomendações de disclosure ambiental internacionais, norte americanas e brasileiras Ângela Rosane Leal de Souza, Ernani Ott, Clóvis Antônio Kronbauer

pelo ISAR/UNCTAD, em 1998, relativo às informações ambientais propõe um amplo disclosure ambiental. Tal disclosure não se restringe somente à divulgação de informações referentes aos custos e passivos ambientais no balanço patrimonial, demonstrativo do resultado do exercício e notas explicativas, mas também propõe que sejam incluídas informações de caráter ambiental em outros relatórios anuais das companhias, bem como em relatório ambiental específico (ISAR/UNCTAD, 1998).

\subsection{Normas e recomendações de evidenciações ambientais norte-americanas}

No âmbito norte-americano, alguns organismos têm se pronunciado a respeito da normatização do disclosure de informações ambientais, tendo emitido diversas regulamentações e recomendações, procurando determinar ou orientar as companhias no sentido de que evidenciem informações relativas ao seu relacionamento com o meio ambiente.

Nos Estados Unidos as companhias devem evidenciar obrigações ambientais materiais às decisões de investimento, sendo que as entidades que não apresentam as evidenciações exigidas podem estar sujeitas a ações de execução civil ou criminal. Além disso, os acionistas e investidores podem ajuizar ações confidenciais contra essas companhias por perdas causadas por declarações falsas ou omissões de informação material.

Segundo Pleva e Gilbertson (2006), as leis e os regulamentos da SEC derivam da noção de que todos os investidores deverão ter acesso às informações que possam influenciar nas decisões de seus investimentos antes da aquisição de ações das companhias. Assim, a SEC requer que as companhias divulguem informações financeiras e não financeiras, de modo que o público possa tomar suas decisões de investimentos. As divulgações dos relatórios anuais são efetuadas através do: (a) Formulário 10-K, um relatório que traz uma avaliação anual dos negócios das companhias norte-americanas; (b) Formulário 20-F, com a mesma finalidade do Formulário $10-\mathrm{K}$, porém traz uma avaliação anual dos negócios das companhias estrangeiras (exceto para as companhias canadenses que devem utilizar o Formulário 40-F). Esses relatórios são de domínio público e podem ser visualizados no website da SEC. 
Um estudo sobre o nível de aderência de companhias do segmento químico e petroquímico às normas e recomendações de disclosure ambiental internacionais, norte americanas e brasileiras Ângela Rosane Leal de Souza, Ernani Ott, Clóvis Antônio Kronbauer

Um resumo das normas e recomendações norte-americanas relativas ao disclosure ambiental exigido naquele país pode ser identificado no Quadro 1, a seguir. Neste quadro pode observar-se inicialmente as normas da SEC, seguidas das exigências emitidas pelo FASB e, por último, apresenta-se o SOP 96-1 emitido pelo AIPCA. Observa-se que o disclosure ambiental exigido nas normas norte-americanas foca na proteção do investidor e não na sustentabilidade como um todo.

\begin{tabular}{|c|c|}
\hline NORMATIVAS & $\begin{array}{l}\text { RESUMO DAS EXIGÊNCIAS DE DISCLOSURE AMBIENTAL NORTE- } \\
\text { AMERICANO }\end{array}$ \\
\hline $\begin{array}{l}\text { SEC - Regulation S-K } \\
\text { Item } 101\end{array}$ & $\begin{array}{l}\text { Requer que as companhias divulguem os efeitos materiais de conformidade com as } \\
\text { legislações ambientais em níveis federal, estadual e local que regulamentam as } \\
\text { descargas de poluentes no ambiente e os investimentos em proteção do ambiente, } \\
\text { da companhia e suas subsidiárias. }\end{array}$ \\
\hline $\begin{array}{l}\text { SEC - Regulation S-K } \\
\text { Item } 103\end{array}$ & $\begin{array}{l}\text { Requer a evidenciação de ações ambientais administrativas ou judiciais, sob } \\
\text { quaisquer das condições qualitativas: (1) materialidade; (2) multas ambientais, } \\
\text { dispêndios de capital e outros encargos que excedem } 10 \% \text { do ativo circulante; ou (3) } \\
\text { obrigação provável maior ou superior que US } \$ 100.000 \text {. }\end{array}$ \\
\hline $\begin{array}{l}\text { SEC - Regulation S-K } \\
\text { Item } 303\end{array}$ & $\begin{array}{l}\text { Embora não trate especificamente de matéria ambiental, exige o relato da } \\
\text { administração e análise das condições financeiras e resultado das operações, } \\
\text { incluindo tendências e incertezas ambientais. }\end{array}$ \\
\hline $\begin{array}{l}\text { SEC - Staff Accounting } \\
\text { Bulletin } 92 \text { (1993) }\end{array}$ & $\begin{array}{l}\text { Determina como devem ser quantificadas as provisões para perdas ambientais, para } \\
\text { que seja possível visualizar seus efeitos sobre a situação financeira da empresa. }\end{array}$ \\
\hline $\begin{array}{l}\text { FASB - SFAS } 5 \\
(1975)\end{array}$ & $\begin{array}{l}\text { Embora não trate especificamente de evidenciações ambientais, este estabelece } \\
\text { padrões de contabilidade relativos às evidenciações de contingências e, tais } \\
\text { conceitos, são estendidos às circunstâncias determinantes do cálculo de } \\
\text { contingências ambientais. Destaca-se que mesmo que uma perda ambiental seja } \\
\text { considerada apenas razoavelmente possível devem ser divulgadas nas notas } \\
\text { explicativas. }\end{array}$ \\
\hline $\begin{array}{l}\text { FASB - EITF 89-13- } \\
\text { Accounting for the Cost of } \\
\text { Asbestos Removal }\end{array}$ & $\begin{array}{l}\text { Emitido em 1989, com o propósito de orientar a capitalização apropriada dos custos } \\
\text { incorridos por uma entidade para tratar de área contaminada por asbesto (sinônimo } \\
\text { de amianto) e sua eliminação das instalações. }\end{array}$ \\
\hline $\begin{array}{l}\text { FASB - EITF } 90-8 \text { - } \\
\text { Capitalization of Costs to } \\
\text { Treat Environmental } \\
\text { Contamination (1990) }\end{array}$ & $\begin{array}{l}\text { Define que os custos do tratamento da contaminação ambiental são aqueles } \\
\text { incorridos por uma entidade para conter, neutralizar, prevenir ou remover a } \\
\text { contaminação ambiental atual ou futura. Tais custos incluem uma gama extensa de } \\
\text { itens, compreendendo desde custos com multas decorrentes do descumprimento de } \\
\text { leis ambientais até custos para prevenir a contaminação ambiental, como custos de } \\
\text { equipamentos para controle da poluição do ar, custos com estudos ambientais, etc. }\end{array}$ \\
\hline $\begin{array}{l}\text { FASB - SFAS } 143 \text { - } \\
\text { Accounting for Asset } \\
\text { Retirement Obligations e } \\
\text { FIN } 47(2001 / 2005)\end{array}$ & $\begin{array}{l}\text { Estabelece padrões de contabilidade para reconhecimento e mensuração de } \\
\text { obrigações nos encerramentos de unidades da empresa ou o desuso de um ativo } \\
\text { tangível. Já a Interpretation } 47 \text { - Accounting for Conditional Asset Retirement } \\
\text { Obligations (FIN 47), emitida em março de 2005, visa sanar os questionamentos que } \\
\text { surgiram a respeito do SFAS } 143 .\end{array}$ \\
\hline $\begin{array}{l}\text { AICPA - SOP 96-1 } \\
\text { (1996) }\end{array}$ & $\begin{array}{l}\text { Pelo American Institute of Certified Public Accountants (AICPA), o Statement of } \\
\text { Position 96-1 - Environmental Remediation Liabilities (SOP 96-1) objetiva orientar } \\
\text { às companhias nos cálculos relativos à responsabilidade associada à reparação de } \\
\text { danos ambientais. }\end{array}$ \\
\hline
\end{tabular}


Um estudo sobre o nível de aderência de companhias do segmento químico e petroquímico às normas e recomendações de disclosure ambiental internacionais, norte americanas e brasileiras Ângela Rosane Leal de Souza, Ernani Ott, Clóvis Antônio Kronbauer

Quadro 1: Resumo do disclosure ambiental norte-americano

Fonte: Elaborado com base na SEC (2006, p. 7-12 e 19-24); FASB (1975); FASB (1989); FASB (1990);

FASB (2001); FASB (2005); AICPA (1996).

Após a apresentação do Quadro 1, cabe ainda destacar que alguns estudos fornecem introspecções na tentativa de verificar a quantidade de companhias que estão divulgando informações ambientais e as variações na divulgação entre companhias. Cita-se um estudo realizado por Bewley (2003), que investigou a relação entre regras da SEC e o disclosure ambiental das indústrias químicas. Os resultados do estudo evidenciaram que há uma associação positiva entre as regras da SEC e disclosure financeiro ambiental, mas não com a informação ambiental não-financeira. Os resultados também sugerem que as diferenças dos métodos de disclosure podem afetar a avaliação dos resultados que são relevantes para estudos futuros relativos à temática.

\subsection{Normas e recomendações de evidenciações ambientais brasileiras}

O IBRACON, por meio da Norma de Procedimento de Auditoria Ambiental n 11 (NPA 11), emitida em 1996, recomenda que os ativos e passivos ambientais sejam identificados e apresentados em títulos específicos, tais como: ativo imobilizado ambiental, estoques ambientais, diferidos ambientais, passivos ambientais, etc. Com relação à posição ambiental da empresa, a NPA 11 menciona que esta deverá ser evidenciada mediante a apresentação de notas explicativas informando: (a) política ambiental adotada; (b) valor dos investimentos em ativos fixos e diferidos ambientais; (c) critérios de amortizações/depreciações; (d) despesas ambientais; (e) passivo contingente e cobertura, se houver, de seguros; e (f) plano diretor de meio ambiente (IBRACON, 1996).

O auditor independente deverá examinar as evidenciações contidas nas demonstrações contábeis e notas explicativas, devendo aprofundar seus procedimentos de auditoria caso as empresas estejam relacionadas às atividades mais poluidoras (ex.: petroquímica, papel e celulose, mineração, etc.). Por fim, a NPA 11 determina ainda 
Um estudo sobre o nível de aderência de companhias do segmento químico e petroquímico às normas e recomendações de disclosure ambiental internacionais, norte americanas e brasileiras Ângela Rosane Leal de Souza, Ernani Ott, Clóvis Antônio Kronbauer

que o auditor requeira a execução de uma auditoria ambiental no caso de aquisições, fusões e incorporações de empresas, e estabelece que este deve acrescentar em seu parecer "um parágrafo em ênfase, ou parecer com ressalva ou até mesmo adverso, pela omissão ou inadequação da divulgação, se seus aspectos forem relevantes" (IBRACON, 1996, p. 5).

O Conselho Federal de Contabilidade (CFC) editou a Resolução ํㅜ 1.003/2004 aprovando a NBC T 15 e instituindo a Demonstração de Informação de Natureza Social e Ambiental, em vigor a partir de $1^{\circ}$ de janeiro de 2006. Essa norma "estabelece procedimentos para a evidenciação de natureza social e ambiental, com o objetivo de demonstrar à sociedade a participação e a responsabilidade social da entidade", definindo que a Demonstração de Informações de Natureza Social e Ambiental deve ser apresentada com dados do exercício atual e anterior, para que seja possível realizar uma comparação entre os exercícios (CFC, 2004 p. 3).

As informações de natureza social e ambiental que devem constar na demonstração instituída pela NBC T 15 são as seguintes: (a) a geração e a distribuição de riqueza; (b) os recursos humanos; (c) a interação da entidade com o ambiente externo; e (d) a interação com o meio ambiente. No âmbito da interação com o meio ambiente, as informações a serem divulgadas são (CFC, 2004 p. 7):

- Investimentos e gastos com manutenção nos processos operacionais para a melhoria do meio ambiente;

- Investimentos e gastos com a preservação e/ou recuperação de ambientes degradados;

- Investimentos e gastos com a educação ambiental para empregados, terceirizados, autônomos e administradores da entidade;

- Investimentos e gastos com educação ambiental para a comunidade;

- Investimentos e gastos com outros projetos ambientais;

- Quantidade de processos ambientais, administrativos e judiciais movidos contra a entidade; 
Um estudo sobre o nível de aderência de companhias do segmento químico e petroquímico às normas e recomendações de disclosure ambiental internacionais, norte americanas e brasileiras Ângela Rosane Leal de Souza, Ernani Ott, Clóvis Antônio Kronbauer

- Valor das multas e das indenizações relativas à matéria ambiental, determinadas administrativa e/ou judicialmente;

- Passivos e contingências ambientais.

A NBC T 15 destaca, ainda, que a empresa poderá acrescentar e detalhar outras informações ao seu critério, e que as informações contábeis contidas nessa demonstração são de responsabilidade técnica de contabilista, devendo ser objeto de auditoria independente.

Assim, pode-se observar que os organismos ligados à área contábil em nível nacional e internacional vêm se pronunciando acerca das evidenciações de natureza ambiental pela contabilidade. Destaca-se que no Brasil a edição de normas e recomendações contábeis relativas à temática é relativamente recente e ainda não existem estudos que verifiquem a aderência a tais normativas.

\section{METODOLOGIA}

Este estudo, conforme a classificação proposta por Gil (1999) se classifica como uma pesquisa exploratória, pois o conhecimento das normas e recomendações de disclosure ambiental, paralelamente, nos níveis internacional, norte-americano e brasileiro, com a identificação do nível de aderência a estas normas e recomendações é ainda pouco conhecido e explorado. Assume também o caráter qualitativo quanto aos procedimentos de análise em relação aos fenômenos estudados, tendo em vista que descreve, analisa e interpreta informações relativas ao disclosure ambiental das empresas, tomando por base os documentos e relatórios que congregam os conjuntos inter-relacionados de dados concernentes ao tema em estudo. Assim sendo, para atingir os objetivos propostos a abordagem da pesquisa é descritiva, e no que concerne aos procedimentos técnicos este estudo classifica-se como documental, em virtude de basear-se nos relatórios anuais e informações tornadas públicas pelas empresas estudadas, valendo-se de materiais que ainda podem ser analisados mais profundamente, de acordo com os objetivos do estudo. 
Um estudo sobre o nível de aderência de companhias do segmento químico e petroquímico às normas e recomendações de disclosure ambiental internacionais, norte americanas e brasileiras Ângela Rosane Leal de Souza, Ernani Ott, Clóvis Antônio Kronbauer

O universo da pesquisa é composto pelas indústrias químicas e petroquímicas emissoras de ADRs, que negociam ações na NYSE e que atuam no Brasil. Dentro do universo proposto, trabalhou-se com uma amostra não-probabilística intencional de 10 companhias, estratificada das indústrias químicas e petroquímicas que se encontram classificadas no ano de 2005 dentre as 42 maiores companhias desse segmento em atuação no Brasil, listadas na edição anual da Revista Exame: Maiores e Melhores 2005 (EXAME, 2006). O Quadro 2 reúne as empresas que compõem a amostra, e que representam $76 \%$ do faturamento do segmento no país:

\begin{tabular}{|c|l|l|r|r|c|c|}
\hline $\begin{array}{c}\text { Rankin } \\
\text { g entre } \\
\text { as 500 } \\
\text { maiore } \\
\mathbf{s}\end{array}$ & $\begin{array}{c}|c| \\
\begin{array}{c}\text { Nome da } \\
\text { Companhia } \\
\text { Setor } \\
\text { Químico/Petroquí } \\
\text { mico }\end{array}\end{array}$ & $\begin{array}{c}\text { Sede da } \\
\text { Companhia no } \\
\text { Brasil }\end{array}$ & $\begin{array}{c}\text { Vendas } \\
\text { (Brasil) } \\
\text { em US\$ } \\
\text { milhões } \\
\text { Ano 2005 }\end{array}$ & $\begin{array}{c}\text { Neg. } \\
\text { Bolsa } \\
\text { BOVESPA }\end{array}$ & $\begin{array}{c}\text { Emite } \\
\mathbf{m} \\
\text { ADRs/ } \\
\text { Ações } \\
\text { NYSE }\end{array}$ & $\begin{array}{c}\text { Controle } \\
\text { Acionário }\end{array}$ \\
\hline 1 & PETROBRAS & $\begin{array}{l}\text { Rio de Janeiro / } \\
\text { RJ }\end{array}$ & $61.457,5$ & Sim & Sim & Brasileiro \\
\hline 9 & BRASKEM & Camaçari / BA & $6.467,3$ & Sim & Sim & Americano \\
\hline 53 & BUNGE & São Paulo / SP & $2.144,9$ & Não & Sim & $\begin{array}{c}\text { Bermudens } \\
\text { e }\end{array}$ \\
\hline 54 & BASF & $\begin{array}{l}\text { São Bern. } \\
\text { Campo / SP }\end{array}$ & $2.043,8$ & Não & Sim & Alemão \\
\hline 71 & DOW BRASIL & São Paulo / SP & $1.612,4$ & Não & Sim & Americano \\
\hline 104 & RHODIA & São Paulo / SP & $1.162,3$ & Não & Sim & Francês \\
\hline 117 & SYNGENTA & São Paulo/SP & $1.071,6$ & Não & Sim & Suíço \\
\hline 132 & MONSANTO & São Paulo / SP & 962,1 & Não & Sim & Americano \\
\hline 143 & DUPONT & Barueri / SP & 915,5 & Não & Sim & Americano \\
\hline 158 & BAYER & São Paulo/ SP & 839,3 & Não & Sim & Alemão \\
\hline
\end{tabular}

Quadro 2: Empresas da amostra classificadas pela posição no ranking entre as 500 maiores companhias brasileiras

Fonte: Edição Anual da Revista Exame: Melhores e Maiores - As 500 maiores empresas do Brasil. Julho, 2006.

Neste estudo as expressões normas e recomendações internacionais são utilizadas para designar aquelas emitidas pelo ISAR/UNCTAD. A utilização das normas deste organismo como parâmetro para as normas e recomendações internacionais, justifica-se pela amplitude das normas na área ambiental emitidas por esse organismo e por este atuar como um grupo de trabalho intergovernamental de especialistas em contabilidade que objetivam a harmonização das práticas contábeis em nível mundial. 
Um estudo sobre o nível de aderência de companhias do segmento químico e petroquímico às normas e recomendações de disclosure ambiental internacionais, norte americanas e brasileiras Ângela Rosane Leal de Souza, Ernani Ott, Clóvis Antônio Kronbauer

Quanto às normas norte-americanas, considera-se o conjunto de normas emitidas nos Estados Unidos pela SEC, pelo FASB e pelo AICPA.

Primeiramente, faz-se a análise da aderência do disclosure ambiental proposto pelo ISAR/UNCTAD, com base nas informações corporativas constantes no conjunto de relatórios divulgados pelas companhias. Foram utilizadas informações tornadas públicas pelas companhias em seus websites e as informações corporativas divulgadas no website da SEC. Tais informações, normalmente, são divulgadas através dos seguintes relatórios: (a) Annual Report ou Corporate Report 2005 (Relatório Anual Corporativo 2005); (b) Financial Report 2005 (Relatório Financeiro 2005); (c) Formulários $10-\mathrm{K}$ e $20-\mathrm{F}$. Num segundo momento verifica-se a aderência do disclosure ambiental às normas norte-americanas (SEC, FASB e AICPA) utilizando-se, exclusivamente, informações divulgadas pelas companhias nos Formulário 10-K e 20-F arquivados junto à SEC. Num terceiro e último momento é verificada a aderência das companhias às normas e recomendações de evidenciação de informações de natureza ambiental emitidas pelo CFC e IBRACON, utilizando-se os relatórios de sustentabilidade, as demonstrações contábeis e demais relatórios anuais publicados no Brasil.

Os registros nas planilhas desenvolvidas para a análise se dão mediante a identificação do nível de aderência de cada companhia em relação a cada item constante na norma/recomendação. Esse nível pode assumir um valor entre 2 (dois) estados possíveis, a saber: (a) aderente; representado pela classificação 1 (um), e empregado quando a companhia atende uma norma ou recomendação; e, (b) não aderente; quando não atendê-la, fato que representado pela classificação 0 (zero). A verificação dos níveis de aderência das companhias aos itens constantes nas normas ou recomendações listadas, estabelece-se pela identificação das informações constantes nos relatórios publicados, e sua vinculação com normas e recomendações dos organismos internacionais, norte-americanos e nacionais, listados nas Tabelas 1, 2 e 3. 
Um estudo sobre o nível de aderência de companhias do segmento químico e petroquímico às normas e recomendações de disclosure ambiental internacionais, norte americanas e brasileiras Ângela Rosane Leal de Souza, Ernani Ott, Clóvis Antônio Kronbauer

\section{ANÁLISE DOS RESULTADOS}

\subsection{Aderência às recomendações de disclosure ambiental do ISAR/UNCTAD}

$\mathrm{Na}$ Tabela 1 apresenta-se a análise da aderência às recomendações de Disclosure ambiental do ISAR/UNTAD por parte das companhias da amostra. Observase que, em média, a aderência das companhias estudadas às normativas do ISAR/UNCTAD atingiu somente $48 \%$.

Tabela 1: Aderência às Recomendações de Disclosure Ambiental do ISAR

\begin{tabular}{|c|c|c|c|c|c|c|c|c|c|c|c|c|c|}
\hline \multicolumn{14}{|c|}{ ADERÊNCIA ÀS NORMAS E RECOMENDAÇÕES DO ISAR/UNCTAD } \\
\hline \multicolumn{2}{|l|}{ Item } & $\begin{array}{l}\text { Disclosure ambiental } \\
\text { modelo ISAR/UNCTAD }\end{array}$ & $\begin{array}{c}\bar{w} \\
\mathbb{D} \\
\infty\end{array}$ & 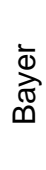 & $\begin{array}{l}\frac{\varepsilon}{\Phi} \\
\frac{1}{\mathscr{N}} \\
\frac{\pi}{\infty}\end{array}$ & $\begin{array}{l}\stackrel{0}{g} \\
\stackrel{5}{5} \\
\oplus\end{array}$ & 3. & $\begin{array}{l}+\frac{7}{0} \\
0 \\
\frac{0}{5} \\
0\end{array}$ & 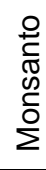 & $\begin{array}{l}0 \\
\frac{\pi}{0} \\
\text { 잉 } \\
\frac{1}{0} \\
0\end{array}$ & 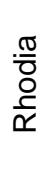 & 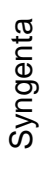 & 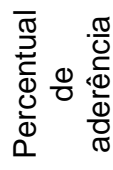 \\
\hline \multirow{3}{*}{$\begin{array}{c}\text { Balanço } \\
\text { Patrimonial }\end{array}$} & 1 & $\begin{array}{l}\text { Ativos / Investimentos } \\
\text { Ambientais }\end{array}$ & 0 & 0 & 0 & 0 & 0 & 0 & 0 & 0 & 0 & 0 & $0 \%$ \\
\hline & 2 & Provisões ambientais & 1 & 1 & 0 & 0 & 1 & 1 & 1 & 1 & 1 & 1 & $80 \%$ \\
\hline & 3 & Recuperação esperada & 1 & 1 & 0 & 0 & 1 & 1 & 0 & 1 & 0 & 0 & $50 \%$ \\
\hline \multirow{2}{*}{ DRE } & 4 & Custo / despesas ambientais & 0 & 0 & 0 & 0 & 0 & 0 & 1 & 0 & 0 & 0 & $10 \%$ \\
\hline & 5 & Receitas ambientais & 0 & 0 & 0 & 0 & 0 & 0 & 0 & 0 & 0 & 0 & $0 \%$ \\
\hline \multirow{3}{*}{$\begin{array}{c}\text { Notas } \\
\text { Explicativa } \\
\text { s }\end{array}$} & 6 & $\begin{array}{l}\text { Ações ambientais adm. ou } \\
\text { judiciais }\end{array}$ & 1 & 1 & 0 & 0 & 1 & 1 & 1 & 1 & 1 & 1 & $80 \%$ \\
\hline & 7 & Contingências ambientais & 0 & 0 & 0 & 0 & 0 & 1 & 0 & 1 & 1 & 1 & $40 \%$ \\
\hline & 8 & $\begin{array}{l}\text { Critérios utilizados para } \\
\text { calcular as provisões }\end{array}$ & 1 & 0 & 0 & 0 & 0 & 1 & 0 & 1 & 1 & 0 & $40 \%$ \\
\hline \multirow{8}{*}{$\begin{array}{l}\text { Relatório } \\
\text { ambiental } \\
\text { ou de } \\
\text { sustentabili } \\
\text {-dade }\end{array}$} & 9 & Escopo do relatório & 1 & 1 & 1 & 0 & 1 & 1 & 0 & 1 & 1 & 1 & $80 \%$ \\
\hline & $\begin{array}{l}1 \\
0 \\
\end{array}$ & Política ambiental da empresa & 1 & 1 & 1 & 0 & 1 & 1 & 0 & 1 & 1 & 1 & $80 \%$ \\
\hline & $\begin{array}{l}1 \\
1\end{array}$ & $\begin{array}{l}\text { Extensão da aderência às } \\
\text { normas estabelecidas em } \\
\text { nível mundial }\end{array}$ & 0 & 1 & 1 & 0 & 1 & 0 & 0 & 1 & 0 & 0 & $40 \%$ \\
\hline & $\begin{array}{l}1 \\
2\end{array}$ & $\begin{array}{l}\text { Questões ambientais chaves } \\
\text { que a companhia está } \\
\text { exposta }\end{array}$ & 0 & 1 & 0 & 0 & 1 & 1 & 0 & 1 & 1 & 1 & $60 \%$ \\
\hline & $\begin{array}{l}1 \\
3\end{array}$ & $\begin{array}{l}\text { Sistema de gerenciamento } \\
\text { ambiental e padrões } \\
\text { internacionais }\end{array}$ & 0 & 1 & 1 & 0 & 1 & 1 & 0 & 1 & 1 & 0 & $60 \%$ \\
\hline & $\begin{array}{l}1 \\
4\end{array}$ & $\begin{array}{l}\text { Desempenho segmentado: } \\
\text { uso de energia, água, } \\
\text { material; emissão de } \\
\text { poluentes, dest. resíduos, etc. }\end{array}$ & 1 & 1 & 1 & 0 & 1 & 0 & 0 & 1 & 1 & 1 & $70 \%$ \\
\hline & $\begin{array}{l}1 \\
5\end{array}$ & $\begin{array}{l}\text { Dados do setor específico, } \\
\text { incluindo indicadores de } \\
\text { desempenho ambiental }\end{array}$ & 0 & 0 & 0 & 0 & 0 & 0 & 0 & 0 & 0 & 0 & $0 \%$ \\
\hline & $\begin{array}{l}1 \\
6\end{array}$ & $\begin{array}{l}\text { Dados financeiros de custos } \\
\text { ambientais }\end{array}$ & 1 & 0 & 0 & 0 & 0 & 0 & 0 & 1 & 0 & 0 & $20 \%$ \\
\hline
\end{tabular}


Um estudo sobre o nível de aderência de companhias do segmento químico e petroquímico às normas e recomendações de disclosure ambiental internacionais, norte americanas e brasileiras Ângela Rosane Leal de Souza, Ernani Ott, Clóvis Antônio Kronbauer

\begin{tabular}{|c|c|c|c|c|c|c|c|c|c|c|c|c|c|}
\hline & 7 & Investimentos ambientais & 1 & 0 & 1 & 0 & 0 & 0 & 0 & 1 & 1 & 0 & $40 \%$ \\
\hline & $\begin{array}{l}1 \\
8\end{array}$ & $\begin{array}{l}\text { Relatório de auditoria } \\
\text { ambiental independente. }\end{array}$ & 1 & 1 & 0 & 0 & 0 & 0 & 0 & 1 & 1 & 1 & $50 \%$ \\
\hline & $\begin{array}{l}1 \\
9\end{array}$ & $\begin{array}{l}\text { Estimativas de recursos } \\
\text { econômicos e benefícios } \\
\text { decorrentes dos esforços com } \\
\text { o meio ambiente }\end{array}$ & 1 & 0 & 1 & 0 & 0 & 0 & 0 & 1 & 0 & 0 & $30 \%$ \\
\hline \multirow{2}{*}{$\begin{array}{l}\text { Relatório } \\
\text { do } \\
\text { Presidente }\end{array}$} & $\begin{array}{l}2 \\
0\end{array}$ & $\begin{array}{l}\text { Melhorias significativas desde } \\
\text { o último relatório }\end{array}$ & 1 & 0 & 1 & 0 & 0 & 0 & 0 & 0 & 0 & 0 & $20 \%$ \\
\hline & $\begin{array}{l}2 \\
1\end{array}$ & $\begin{array}{l}\text { Compromisso da companhia } \\
\text { com a melhoria ambiental } \\
\text { contínua }\end{array}$ & 1 & 1 & 1 & 0 & 1 & 1 & 0 & 1 & 1 & 0 & $70 \%$ \\
\hline \multirow{2}{*}{$\begin{array}{c}\text { Relatório } \\
\text { por } \\
\text { Segmento } \\
\text { de } \\
\text { Negócios } \\
\end{array}$} & $\begin{array}{l}2 \\
2\end{array}$ & $\begin{array}{l}\text { Dados segmentados do } \\
\text { desempenho das questões do } \\
\text { meio ambiente }\end{array}$ & 1 & 1 & 1 & 0 & 1 & 0 & 0 & 1 & 1 & 1 & $70 \%$ \\
\hline & $\begin{array}{l}2 \\
3 \\
\end{array}$ & $\begin{array}{l}\text { Melhorias nas áreas chaves } \\
\text { desde o último relatório }\end{array}$ & 1 & 1 & 1 & 0 & 1 & 0 & 0 & 1 & 1 & 1 & $70 \%$ \\
\hline \multirow{2}{*}{$\begin{array}{l}\text { Relatório } \\
\text { de } \\
\text { Administra } \\
\text {-ção ou } \\
\text { Diretoria }\end{array}$} & $\begin{array}{l}2 \\
4\end{array}$ & $\begin{array}{l}\text { Posição da empresa com } \\
\text { referência às tendências e } \\
\text { incertezas ambientais. }\end{array}$ & 1 & 1 & 1 & 0 & 1 & 1 & 0 & 1 & 1 & 1 & $80 \%$ \\
\hline & $\begin{array}{l}2 \\
5 \\
\end{array}$ & $\begin{array}{l}\text { Declaração da política } \\
\text { ambiental }\end{array}$ & 1 & 1 & 1 & 0 & 1 & 0 & 0 & 1 & 1 & 1 & $70 \%$ \\
\hline \multirow{3}{*}{$\begin{array}{c}\text { Relatório } \\
\text { Financeiro } \\
e \\
\text { Operaciona } \\
\text { I } \\
\end{array}$} & $\begin{array}{l}2 \\
6\end{array}$ & $\begin{array}{l}\text { Processo de mudança de } \\
\text { tratamento requerida por } \\
\text { exigência legal futura. }\end{array}$ & 1 & 0 & 0 & 1 & 0 & 1 & 0 & 1 & 1 & 0 & $50 \%$ \\
\hline & $\begin{array}{l}2 \\
7 \\
\end{array}$ & $\begin{array}{l}\text { Nível atual e projetado dos } \\
\text { gastos ambientais }\end{array}$ & 0 & 0 & 0 & 0 & 1 & 1 & 1 & 0 & 0 & 0 & $30 \%$ \\
\hline & & $\begin{array}{c}\text { Percentual de aderência } \\
\text { médio }\end{array}$ & $\begin{array}{l}67 \\
\% \\
\end{array}$ & $\%$ & $\begin{array}{l}48 \\
\%\end{array}$ & $\begin{array}{l}4 \\
\% \\
\end{array}$ & $\begin{array}{l}56 \\
\%\end{array}$ & $\begin{array}{l}48 \\
\%\end{array}$ & $\begin{array}{l}15 \\
\%\end{array}$ & $\begin{array}{l}78 \\
\%\end{array}$ & $\begin{array}{l}63 \\
\% \\
\end{array}$ & $\begin{array}{l}44 \\
\%\end{array}$ & $48 \%$ \\
\hline
\end{tabular}

Fonte: Dados da pesquisa, 2006.

O nível de aderência identificado (48\%), revela que o propósito do ISAR de aumentar o nível de evidenciações e promover a harmonização internacional de revelação de informações ambientais das companhias, auxiliando na implementação das melhores práticas para satisfazer requisitos internacionais nesta área, não foi atendido em sua plenitude.

Examinando-se a aderência por parte das companhias, constata-se que a Petrobras apresenta o maior nível de aderência (78\%), seguida das companhias Basf e da Rhodia, com 67\% e 63\%, respectivamente. Isto demonstra que algumas companhias já começam a evidenciar uma maior quantidade de informações de natureza ambiental, porém para outras a evidenciação ambiental ainda é incipiente, como é o caso das companhias Bunge e Monsanto, que apresentaram níveis de aderência extremamente reduzidos (4\% e $15 \%$, respectivamente). 
Um estudo sobre o nível de aderência de companhias do segmento químico e petroquímico às normas e recomendações de disclosure ambiental internacionais, norte americanas e brasileiras Ângela Rosane Leal de Souza, Ernani Ott, Clóvis Antônio Kronbauer

Também se observa que alguns itens específicos do disclosure são contemplados com uma maior divulgação. Nesse sentido, os itens que apresentam maior nível de aderência às normas e recomendações do ISAR são as evidenciações de provisões ambientais (item 2); ações ambientais, administrativas ou judiciais (item 6); escopo do relatório (item 9); política ambiental da empresa (item 10); e o relato da administração sobre a posição da empresa com referência às tendências e incertezas ambientais (item 24), todos com $80 \%$ de aderência. Em contrapartida, alguns itens relacionados aos dados quantitativos como a evidenciação de ativos/investimentos ambientais (item 1); custos/despesas ambientais (item 4); e receitas ambientais (item 5), apresentam aderência igual ou próxima de zero. Esse resultado assemelha-se ao de pesquisas anteriores que também constataram a carência de dados quantitativos de natureza ambiental através das contas do balanço patrimonial e demonstração de resultado do exercício (Nossa, 2002; Calixto, 2004).

\subsection{Aderência às normas de disclosure ambiental norte-americanas}

$\mathrm{Na}$ Tabela 2 apresenta-se a análise da aderência do disclosure ambiental das companhias da amostra às normas norte-americanas, considerando-se o conjunto de normativas emitidas pela SEC, FASB e AICPA.

Com base nos dados da Tabela 2, constata-se que, no conjunto, as companhias da amostra apresentam uma aderência parcial às normativas e recomendações de organismos norte-americanos equivalente a $69 \%$, porém pode ser percebido que os níveis de aderência a cada alínea são diferenciados. 
Um estudo sobre o nível de aderência de companhias do segmento químico e petroquímico às normas e recomendações de disclosure ambiental internacionais, norte americanas e brasileiras Ângela Rosane Leal de Souza, Ernani Ott, Clóvis Antônio Kronbauer

Tabela 2: Aderência às Normas de Disclosure Ambiental Norte-americanas

\begin{tabular}{|c|c|c|c|c|c|c|c|c|c|c|c|c|}
\hline \multicolumn{13}{|c|}{ ADERÊNCIA ÀS NORMAS E RECOMENDAÇÕES NORTE-AMERICANAS } \\
\hline & $\begin{array}{l}\text { Disclosure ambiental } \\
\text { SEC , FASB e AICPA }\end{array}$ & $\begin{array}{c}\overline{\mathscr{D}} \\
\tilde{\mathbb{D}}\end{array}$ & 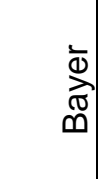 & 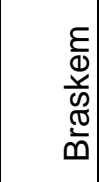 & $\begin{array}{l}\mathscr{D} \\
\vdots \\
\vdots \\
\overline{0}\end{array}$ & 3 & $\begin{array}{l}+ \\
\overline{0} \\
0 \\
\bar{D}\end{array}$ & 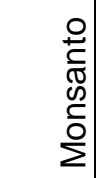 & 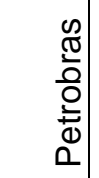 & $\begin{array}{l}\frac{\pi}{\bar{z}} \\
\frac{0}{\tilde{\Upsilon}}\end{array}$ & 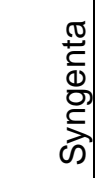 & 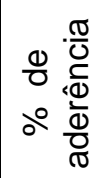 \\
\hline 1 & $\begin{array}{l}\text { Efeitos materiais de } \\
\text { conformidade com as } \\
\text { legislações federais, } \\
\text { estaduais e municipais }\end{array}$ & 1 & 1 & 1 & 1 & 1 & 1 & 1 & 1 & 1 & 1 & $\begin{array}{c}100 \\
\%\end{array}$ \\
\hline 2 & $\begin{array}{l}\text { Investimentos efetuados } \\
\text { para a proteção do meio } \\
\text { ambiente }\end{array}$ & 0 & 0 & 1 & 0 & 1 & 0 & 0 & 1 & 1 & 0 & $40 \%$ \\
\hline 3 & $\begin{array}{l}\text { Ações ambientais } \\
\text { materiais, administrativas } \\
\text { ou judiciais }\end{array}$ & 1 & 1 & 0 & 0 & 1 & 1 & 1 & 1 & 1 & 1 & $80 \%$ \\
\hline 4 & $\begin{array}{l}\text { Relato da administração } \\
\text { sobre posição da empresa } \\
\text { com referência às } \\
\text { tendências e incertezas } \\
\text { ambientais }\end{array}$ & 1 & 0 & 1 & 0 & 1 & 1 & 0 & 1 & 1 & 0 & $60 \%$ \\
\hline 5 & $\begin{array}{l}\text { Provisões para perdas } \\
\text { ambientais }\end{array}$ & 1 & 1 & 0 & 0 & 1 & 1 & 1 & 1 & 1 & 1 & $80 \%$ \\
\hline 6 & Contingências ambientais & 0 & 0 & 0 & 0 & 0 & 0 & 1 & 1 & 1 & 1 & $40 \%$ \\
\hline 7 & Custos ambientais & 1 & 0 & 1 & 0 & 1 & 1 & 1 & 1 & 1 & 0 & $70 \%$ \\
\hline 8 & $\begin{array}{l}\text { Evidenciação de valores } \\
\text { relacionados à correção e } \\
\text { eliminação de ativos }\end{array}$ & 1 & 1 & 0 & 1 & 1 & 1 & 1 & 1 & 1 & 0 & $80 \%$ \\
\hline & $\begin{array}{l}\text { Percentual de aderência } \\
\text { médio }\end{array}$ & $75 \%$ & $50 \%$ & $50 \%$ & $25 \%$ & $88 \%$ & $75 \%$ & $75 \%$ & $\begin{array}{c}100 \\
\%\end{array}$ & $\begin{array}{c}100 \\
\%\end{array}$ & $50 \%$ & $69 \%$ \\
\hline
\end{tabular}

Fonte: Dados da pesquisa, 2006.

Ainda na Tabela 2, observa-se também que somente a alínea 'a', que se refere à evidenciação dos efeitos materiais de conformidade com as legislações federais, estaduais e municipais apresenta aderência plena, ou seja, 100\% das companhias evidenciam tais efeitos. As normativas com percentual de aderência acima da média geral foram: as ações ambientais materiais, administrativas ou judiciais (alínea ' $c$ '); as provisões para perdas ambientais (alínea 'e'); e a evidenciação de valores relacionados à correção e à eliminação (abandono) de ativos (alínea ' $h$ '); todas com 80\% de aderência. 
Um estudo sobre o nível de aderência de companhias do segmento químico e petroquímico às normas e recomendações de disclosure ambiental internacionais, norte americanas e brasileiras Ângela Rosane Leal de Souza, Ernani Ott, Clóvis Antônio Kronbauer

As informações relacionadas ao relato da administração sobre a posição da companhia com referência às tendências e às incertezas ambientais (alínea 'd') e as relativas à evidenciação dos custos ambientais (alínea ' $g$ '), apresentam uma aderência próxima da média geral, ou seja, de $70 \%$ e 60\%, respectivamente. Menores percentuais são observados nas informações relativas aos investimentos que visam à proteção do meio ambiente (alínea 'b') e às contingências ambientais (alínea 'f'), cada um com $40 \%$ de aderência.

Com relação aos resultados dos níveis de aderência às normas de disclosure ambiental norte-americano por parte das companhias, observa-se que somente a Petrobras e a Rhodia são integralmente aderentes, seguidas da Dow com 88\%; e da Basf, DuPont e Monsanto com 75\% de aderência cada uma. Já a Bayer, a Braskem e a Syngenta apresentam um nível de $50 \%$ de aderência. Por último, destaca-se pelo baixo nível de aderência a Bunge (25\%).

Esses resultados corroboram os estudos de Pleva e Gilbertson (2006) e Sutherland (2002), que constataram deficiências nos disclosures ambientais das companhias que arquivam seus relatórios na SEC. A não evidenciação de informações ambientais pelas companhias não significa, necessariamente, que elas não tenham obrigações ou investimentos nesse âmbito; significa somente que são menos transparentes.

\subsection{Aderência às normas de disclosure ambiental brasileiras}

Como tratado no referencial teórico, o CFC e o IBRACON estabelecem normas para as evidenciações ambientais no âmbito da contabilidade brasileira. O CFC estabelece a inclusão de evidenciações financeiras e de fatos ambientais que possam impactar na situação econômico-financeira das companhias na Demonstração de Informações de Natureza Social e Ambiental. Já o IBRACON propõe a evidenciação de informações ambientais no balanço patrimonial e nas notas explicativas.

$\mathrm{Na}$ Tabela 3 podem ser observados os resultados obtidos na análise de aderência das evidenciações, efetuadas nas demonstrações contábeis e notas explicativas publicadas no Brasil pelas companhias pertencentes a amostra, às normas 
Um estudo sobre o nível de aderência de companhias do segmento químico e petroquímico às normas e recomendações de disclosure ambiental internacionais, norte americanas e brasileiras Ângela Rosane Leal de Souza, Ernani Ott, Clóvis Antônio Kronbauer

e recomendações de evidenciações de informações ambientais brasileiras propostas por esses dois organismos que regulamentam a profissão contábil.

Pela análise da referida tabela, pode-se observar que as recomendações do Conselho Federal de Contabilidade relativas à evidenciação da quantidade de processos ambientais, administrativos e judiciais movidos contra a entidade (item 6) e o valor das multas e das indenizações relativas à matéria ambiental via administrativa ou judicial (item 7), não foram observadas pelas companhias na demonstração de informações de natureza social e ambiental. Desta observação, pode-se inferir que as más notícias relacionadas ao desempenho ambiental das companhias não são evidenciadas nos seus relatórios de sustentabilidade ou ambiental.

Já as alíneas relacionadas aos investimentos ambientais (itens 1, 2, 4 e 5) apresentaram níveis de aderência entre $40 \%$ e $50 \%$, à exceção do item 3 que se refere aos investimentos com educação ambiental para empregados, terceirizados, autônomos e administradores da entidade, cujo nível de aderência foi de apenas $20 \%$.

Tabela 3: Aderência às Normas e Recomendações de Disclosure Ambiental Brasileiras

\begin{tabular}{|c|c|c|c|c|c|c|c|c|c|c|c|c|c|c|}
\hline & & & ADERÊNCIA ÀS NORMAS & EC & $\mathrm{M}$ & ND & E & B & RAS & LEIF & & & & \\
\hline & & Dis & $\begin{array}{l}\text { closure ambiental } \\
\text { CFC e IBRACON }\end{array}$ & $\begin{array}{l}\overline{\mathscr{D}} \\
\mathbb{\mathscr { D }}\end{array}$ & 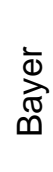 & $\begin{array}{l}\frac{\varepsilon}{d} \\
\frac{\grave{L}}{\omega} \\
\frac{\pi}{\omega}\end{array}$ & $\begin{array}{l}0 \\
\stackrel{0}{5} \\
\stackrel{5}{5}\end{array}$ & 3 & 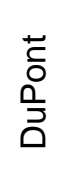 & 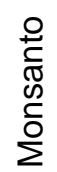 & $\begin{array}{l}0 \\
\frac{\pi}{0} \\
0 \\
0 \\
\frac{0}{0} \\
0\end{array}$ & $\begin{array}{l}\frac{\pi}{\overline{0}} \\
\frac{0}{\tilde{x}}\end{array}$ & 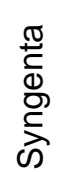 & 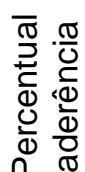 \\
\hline 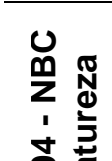 & $\begin{array}{l}0 \\
0 \\
0, \frac{\pi}{\pi} \\
i 0 \\
0\end{array}$ & 1 & $\begin{array}{l}\text { Investimentos e gastos com } \\
\text { manutenção nos processos } \\
\text { operacionais para melhoria } \\
\text { do meio ambiente. }\end{array}$ & 1 & 0 & 1 & 1 & 0 & 0 & 1 & 1 & 0 & 0 & $\begin{array}{l}50 \\
\%\end{array}$ \\
\hline 兽 zo & 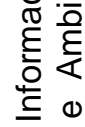 & 2 & $\begin{array}{l}\text { Investimentos e gastos com } \\
\text { prevenção e/ou recuperação } \\
\text { de ambientes degradados. }\end{array}$ & 1 & 0 & 1 & 1 & 0 & 0 & 0 & 1 & 0 & 0 & $\begin{array}{l}40 \\
\%\end{array}$ \\
\hline 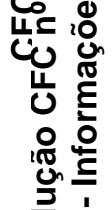 & 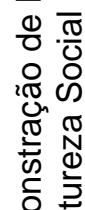 & 3 & $\begin{array}{l}\text { Investimentos e gastos com } \\
\text { educação ambiental para } \\
\text { empregados, terceirizados, } \\
\text { autônomos e } \\
\text { administradores da entidade. }\end{array}$ & 0 & 0 & 0 & 1 & 0 & 0 & 0 & 1 & 0 & 0 & $\begin{array}{l}20 \\
\%\end{array}$ \\
\hline d & $\frac{\sum_{0}}{d} \frac{\pi}{2}$ & 4 & $\begin{array}{l}\text { Investimentos e gastos com } \\
\text { educação ambiental para a } \\
\text { comunidade }\end{array}$ & 0 & 0 & 1 & 1 & 0 & 0 & 1 & 1 & 0 & 0 & $\begin{array}{l}40 \\
\%\end{array}$ \\
\hline
\end{tabular}


Um estudo sobre o nível de aderência de companhias do segmento químico e petroquímico às normas e recomendações de disclosure ambiental internacionais, norte americanas e brasileiras Ângela Rosane Leal de Souza, Ernani Ott, Clóvis Antônio Kronbauer

\begin{tabular}{|c|c|c|c|c|c|c|c|c|c|c|c|c|c|c|}
\hline & & 5 & $\begin{array}{l}\text { Investimentos e gastos com } \\
\text { outros projetos ambientais. }\end{array}$ & 1 & 0 & 1 & 0 & 0 & 0 & 1 & 1 & 0 & 0 & $\begin{array}{l}40 \\
\%\end{array}$ \\
\hline & & 6 & $\begin{array}{l}\text { Quantidades de processos } \\
\text { ambientais, administrativos e } \\
\text { judiciais movidos contra a } \\
\text { entidade. }\end{array}$ & 0 & 0 & 0 & 0 & 0 & 0 & 0 & 0 & 0 & 0 & $0 \%$ \\
\hline & & 7 & $\begin{array}{l}\text { Valor das multas e das } \\
\text { indenizações relativas a } \\
\text { matéria ambiental via } \\
\text { administrativa ou judicial. } \\
\end{array}$ & 0 & 0 & 0 & 0 & 0 & 0 & 0 & 0 & 0 & 0 & $0 \%$ \\
\hline & & 8 & $\begin{array}{l}\text { Passivos e Contingências } \\
\text { Ambientais } \\
\end{array}$ & 0 & 0 & 0 & 0 & 0 & 0 & 0 & 1 & 0 & 0 & $\begin{array}{l}10 \\
\%\end{array}$ \\
\hline & & 9 & $\begin{array}{l}\begin{array}{l}\text { Revisão do auditor } \\
\text { independente }\end{array} \\
\end{array}$ & 0 & 0 & 0 & 0 & 0 & 0 & 0 & 1 & 0 & 0 & $\begin{array}{l}10 \\
\% \\
\end{array}$ \\
\hline \multirow{7}{*}{ 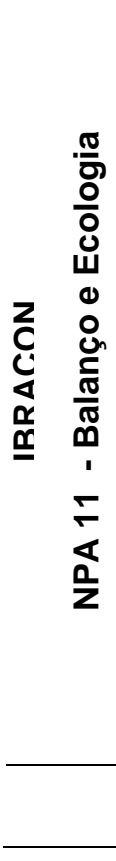 } & \multirow{2}{*}{ 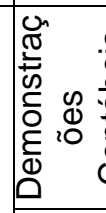 } & $\begin{array}{l}1 \\
0\end{array}$ & Ativos Ambientais & 0 & 0 & 0 & 0 & 0 & 0 & 0 & 0 & 0 & 0 & $0 \%$ \\
\hline & & $\begin{array}{l}1 \\
1\end{array}$ & $\begin{array}{l}\text { Passivos Ambientais ou } \\
\text { Plano Diretor de Meio } \\
\text { Ambiente. }\end{array}$ & 1 & 0 & 0 & 0 & 0 & 0 & 0 & 1 & 0 & 0 & $\begin{array}{l}20 \\
\%\end{array}$ \\
\hline & \multirow{3}{*}{ 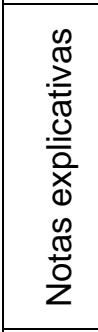 } & \begin{tabular}{l|}
1 \\
2 \\
\end{tabular} & $\begin{array}{l}\text { Retorno sobre Investimento } \\
\text { Ambiental }\end{array}$ & 0 & 0 & 0 & 0 & 0 & 0 & 0 & 0 & 0 & 0 & $0 \%$ \\
\hline & & \begin{tabular}{|l|}
1 \\
3 \\
\end{tabular} & $\begin{array}{l}\text { Posição ambiental da } \\
\text { empresa }\end{array}$ & 0 & 0 & 1 & 0 & 0 & 0 & 0 & 1 & 0 & 0 & $\begin{array}{l}20 \\
\%\end{array}$ \\
\hline & & $\begin{array}{l}1 \\
4\end{array}$ & $\begin{array}{l}\text { Contingências ambientais } \\
\text { (no caso de empresa } \\
\text { reconhecidamente } \\
\text { poluidora). }\end{array}$ & 0 & 0 & 0 & 0 & 0 & 0 & 0 & 1 & 0 & 0 & $\begin{array}{l}10 \\
\%\end{array}$ \\
\hline & $\begin{array}{l}\frac{0}{\frac{0}{2}} \\
\frac{.0}{\overline{0}} \\
\frac{2}{2}\end{array}$ & $\begin{array}{l}1 \\
5\end{array}$ & $\begin{array}{l}\text { Auditoria da informações } \\
\text { ambientais nas } \\
\text { demonstrações contábeis e } \\
\text { auditoria ambiental no caso } \\
\text { de aquisições, fusões e } \\
\text { incorporações. }\end{array}$ & 0 & 0 & 0 & 0 & 0 & 0 & 0 & 1 & 0 & 0 & $\begin{array}{l}10 \\
\%\end{array}$ \\
\hline & & & $\begin{array}{c}\text { Percentual de aderência } \\
\text { médio }\end{array}$ & $\begin{array}{l}27 \\
\% \\
\end{array}$ & $\begin{array}{l}0 \\
\% \\
\end{array}$ & $\begin{array}{l}33 \\
\%\end{array}$ & $\begin{array}{l}27 \\
\% \\
\end{array}$ & $\begin{array}{l}0 \\
\% \\
\end{array}$ & $\begin{array}{l}0 \\
\% \\
\end{array}$ & $\begin{array}{l}20 \\
\%\end{array}$ & $\begin{array}{l}73 \\
\% \\
\end{array}$ & $\begin{array}{l}0 \\
\% \\
\end{array}$ & $\begin{array}{l}0 \\
\% \\
\end{array}$ & $\begin{array}{l}18 \\
\%\end{array}$ \\
\hline
\end{tabular}

Fonte: Dados da pesquisa, 2006.

Quanto às recomendações do IBRACON, no que se refere à evidenciação de ativos ambientais e dos retornos dos investimentos ambientais nas demonstrações contábeis e nas notas explicativas, percebe-se pela observância da Tabela 3, que estas não foram obedecidas pelas companhias. Os demais itens também apresentam um baixo nível de aderência do disclosure ambiental preconizado pelo IBRACON. Percebese que as demonstrações contábeis, ao contrário do que é defendido por diversos autores (Martins; De Luca, 1994; Ribeiro, 2005; Tinoco; Kraemer, 2004; Ferreira, 2003), 
Um estudo sobre o nível de aderência de companhias do segmento químico e petroquímico às normas e recomendações de disclosure ambiental internacionais, norte americanas e brasileiras Ângela Rosane Leal de Souza, Ernani Ott, Clóvis Antônio Kronbauer

não têm sido utilizadas pelas companhias da amostra como elemento de evidenciação dos itens relacionados com as questões de caráter ambiental.

Cabe destacar que companhias que se constituem juridicamente no Brasil como sociedades limitadas, não estão obrigadas a publicar suas demonstrações contábeis. É o que ocorre com as companhias Bayer, Monsanto, Rhodia e Syngenta. Tal fato contribuiu para reduzir o percentual de aderência às normas do IBRACON, embora as companhias que divulgaram suas demonstrações contábeis obrigatórias tenham apresentado baixos níveis de aderência às recomendações de evidenciação ambiental brasileiras.

Por último, destaca-se que a maioria das companhias (80\%) não divulgou seus passivos ambientais nas demonstrações contábeis. Nesse sentido, cabe ressaltar que em virtude do alto potencial poluidor do segmento, a omissão de registros de passivos ambientais, resultantes de práticas comuns que não costumam reconhecer e evidenciar responsabilidades pela degradação ambiental poderá encobrir a existência de passivos ambientais (passivos ocultos).

\section{CONSIDERAÇÕES FINAIS}

No exame do referencial bibliográfico utilizado para elaboração deste estudo, pôde-se constatar que nos Estados Unidos da América as normas de disclosure ambiental editadas pela SEC, FASB e AICPA (SOP 96-1), são de observância obrigatória pelas companhias que arquivam seus relatórios anuais junto à SEC (Formulários 10-K e 20-F). As recomendações do ISAR/UNCTAD foram editadas com o propósito de servir de orientação para a prática de disclosure ambiental pelas companhias e órgãos reguladores de diversas nações, porém são de observância voluntária. Estas, no entanto, são bem mais detalhadas que as normas de disclosure ambiental norte-americanas. No âmbito brasileiro, as normas de evidenciação de informações de natureza ambiental editadas pelo CFC e pelo IBRACON, além de requererem um detalhamento inferior ao detalhamento proposto pelo ISAR/UNCTAD, também são de adesão voluntária. 
Um estudo sobre o nível de aderência de companhias do segmento químico e petroquímico às normas e recomendações de disclosure ambiental internacionais, norte americanas e brasileiras Ângela Rosane Leal de Souza, Ernani Ott, Clóvis Antônio Kronbauer

$\mathrm{Na}$ pesquisa exploratória realizada numa amostra de 10 companhias de nível mundial pertencentes ao segmento químico e petroquímico, visando examinar o disclosure ambiental frente às normativas e recomendações dos organismos citados, comprovou-se que a aderência às normas e recomendações de disclosure ambiental do ISAR/UNCTAD, em média, não atingiu 50\%. No que concerne às normas emitidas pela SEC, FASB e AICPA, o nível de aderência pelas companhias foi mais expressivo, tendo atingido $69 \%$ em média. Este percentual perde expressão quando se sabe que as referidas normas são de adoção obrigatória. O nível de aderência das companhias às recomendações de disclosure emanadas do CFC e do IBRACON foi bastante baixo, com exceção da Petrobras que atingiu um nível de evidenciação equivalente a $73 \%$. Pode ter contribuído para o baixo nível de aderência, o fato de que diversas companhias estão constituídas no Brasil sob a natureza jurídica de sociedades limitadas, não sujeitas à publicação de demonstrações contábeis.

Os resultados obtidos no estudo revelam, finalmente, que as organizações tendem a divulgar informações relacionadas com as questões ambientais quando o seu cumprimento é de caráter obrigatório.

\section{REFERÊNCIAS}

AICPA. American Institute of Certified Public Accountants. (1996). Statement of Position 96-1 (SOP 96-1): Environmental Remediation Liabilities. Disponível em: <http://www.aicpa.org/states/stmap.htm>. Acesso em: 16/maio/2006.

ANDRADE, Sueli Amália. (2001). Educação ambiental - considerações gerais sobre a problemática ambiental. (2 ed.). (ampliada) Brasília, Ministério do Meio ambiente.

BERTHELOT, Sylvie; CORMIER, Denis; MAGNAN, Michel. (2003). Environmental disclosure research: review and synthesis. Journal of Accounting Literature. Disponível em: http://www.findarticles.com/p/articles/mi_qa3706/is_200301/ai_n9209035. Acesso em: 23/mar/2006.

BEWLEY, Kathryn. (2003). SEC regs and environmental disclosure. In: Proceedings of the Annual Conference of the Administrative Sciences Association of Canada, June 1417. 
Um estudo sobre o nível de aderência de companhias do segmento químico e petroquímico às normas e recomendações de disclosure ambiental internacionais, norte americanas e brasileiras Ângela Rosane Leal de Souza, Ernani Ott, Clóvis Antônio Kronbauer

BRASIL. (2000). LEI N.o 10.165, de 27 de dezembro de 2000. Altera a Lei no 6.938, de 31 de agosto de 1981, que dispõe sobre a Política Nacional do Meio Ambiente. Disponível em: <http://www.portaltributario.com.br/legislacao/lei10165.htm>. Acesso em: 14/jan/2006.

BURRITT, Roger L.; WELCH, Stephen. (1997). Australian commonwealth entities: an analysis of their environmental disclosures. Abacus. v. 33. n. 1, p. 1-19.

CALIXTO, Laura. (2004). Contabilidade Ambiental: aplicação do modelo ISAR no setor de mineração. 147 f. (Dissertação de Mestrado). Faculdade de Administração e Finanças, Universidade do Estado do Rio de Janeiro, Rio de Janeiro.

CFC - Conselho Federal de Contabilidade. (2004). Resolução n. 1.003/04 - Aprova a NBC T 15 - Dispõe sobre Informações de Natureza Social e Ambiental.

CHAN-FISHEL, Michelle. (2003). SEC and social/environmental accounting. Corporate Sunshine Working Group Bulletin, set/03. Disponível em: www.environmentalfinance.com/2003/0309sep/disclsre.htm. Acesso em: 12/out/2006.

CICA - Canadian Institute of Chartered Accountants. (1993). Environmental cost and liabilities: Accounting and Financial Reporting. Disponível em: <http://www.cica.ca/index.cfm/ci_id/8277/la_id/1.htm>. Acesso em: 8/nov/2005.

DEEGAN, Craig; RANKING, Michaela. (1996). Do Australian companies report environmental news objectively? An analysis of environmental disclosures by firms prosecuted successfully by the environmental protection authority. Accounting, Auditing \& Accountability Journal, v. 9, n. 2, p. 50-67.

EMERY, Anthony R.T. (2002). The challenge of environmental accounting. Teaching Business \& Economics. Autumn. Disponível em: < http://www.findarticles.com/p/articles/mi_qa3889/is_2002 10/ai_n9137054>. Acesso em: $6 /$ nov/2006.

FASB - Financial Accounting Standards Board. Institucional. Disponível em: <http://www.fasb.org/>. Acesso em: 20/abr/2006.

. (1975). SFAS 5 - Statement N. $\cong$ 5: Accounting for contingencies. Mar. Disponível em: <http://www.fasb.org/pdf/fas5.pdf>. Acesso em: 21/out/2006.

. (1989). EITF 89-13: Accounting for the cost of asbestos removal. 26 out. Disponível em: <http://www.fasb.org/pdf/abs89-13.pdf>. Acesso em: 21/out/2006. 
Um estudo sobre o nível de aderência de companhias do segmento químico e petroquímico às normas e recomendações de disclosure ambiental internacionais, norte americanas e brasileiras Ângela Rosane Leal de Souza, Ernani Ott, Clóvis Antônio Kronbauer

. (1990). EITF 90-8: Capitalization of costs to treat environmental contamination. Maio/jul. 1990. Disponível em: <http://www.fasb.org/pdf/abs90-8.pdf>. Acesso em: 15/out/2006.

. (2001). SFAS 143 - Statement N․․ 143: Accounting for asset retirement obligations. Jun. Disponível em: <http://www.fasb.org/pdf/fas143.pdf>. Acesso em: 21/Out/2006.

FEE - Fédération des Experts Comptables Européens. Institucional. Disponível em: <http://www.fee.be/>. Acesso em: 14/abr/2006.

FERREIRA, Aracéli Cristina de Souza. (1998). Uma contribuição para a gestão econômica do meio ambiente: um enfoque sistêmico da informação. (Tese de Doutorado). Faculdade de Economia, Administração e Contabilidade, Universidade de São Paulo, SP.

(2003). Contabilidade ambiental: uma informação para o desenvolvimento sustentável. São Paulo: Atlas.

GAMBLE, George O.; HSU, Kate, KIT, Devaun; RADTKE, Robin R. (1995). Environmental disclosure in annual reports and 10-Ks: An examination. Accounting Horizons, v. 9, n. 3, p. 34-54.

GIL, Antonio Carlos. (1999). Métodos e técnicas de pesquisa social. (5 ed.). São Paulo: Atlas.

GRAY, Rob. (1994). Accounting for the environment. Princeton: Markus Wiener Publischer.

GONZÁLEZ, Carlos Larrinaga; MONEVA, José Mariano Abadía; MARACULLÁ, Fernando Llena; FENECH, Francisco Carrasco; RUIZ, Carmen Correa. (2002). Regulación contable de la información medioambiental. Normativa española e internacional. AECA, Madrid.

GUESSER, Jaqueline Manes; BEUREN, Ilse Maria. (1998). Caracterização e mensuração dos custos ambientais. Contabilidade Vista \& Revista. Belo Horizonte, v .9, n. 3. p. 25-31, set.

HACKSTON, David; MILNE, Markus J. (1996). Some determinants of social and environmental disclosures in New Zealand companies. Accounting, Auditing \& Accountability Journal, v. 9, n. 1, p. 77-108. 
Um estudo sobre o nível de aderência de companhias do segmento químico e petroquímico às normas e recomendações de disclosure ambiental internacionais, norte americanas e brasileiras Ângela Rosane Leal de Souza, Ernani Ott, Clóvis Antônio Kronbauer

IBRACON. (1996). NPA 11 - Normas e procedimentos de auditoria - Balanço e ecologia. São Paulo: Ibracon. Disponível em: <http://www.ibracon.com.br/>. Acesso em: 18/abr/2006.

ICAC. (2002). Resolución de 25 de marzo de 2002 del Instituto de Contabilidad y Auditoría de Cuentas: por la que se aprueban normas para el reconocimiento, valoración e información de los aspectos medioambientales en las cuentas anuales. Disponível em: <http://www.icac.meh.es/consultas/MEDIOAMB.HTM>. Acesso em: 26/abr/2006.

INGRAM, Robert. W.; FRAZIER, Katherine Beal. (1980). Environmental performance and corporate disclosure. Journal of Accounting Research, v. 18, n. 2, p. 514-622.

ISAR/UNCTAD. (1998). Accounting and financial reporting for environmental costs and liabilities. Disponível em: <http://www.unctad.org/TEMPLATES/\&lang=1>. Acesso em: 21/out/2005.

LÜDKE, Menga; ANDRÉ, Marli. (1986). Pesquisa em educação: abordagens qualitativas. São Paulo: E.P.U.

MARTINS, Eliseu; DE LUCA, Márcia M. (1994). Ecologia via contabilidade. Revista Brasileira de Contabilidade, Brasília - DF: ano 23, n. 86, mar/94, p.20-29.

NOSSA, Valcemiro. (2002). Disclosure ambiental: uma análise do conteúdo dos relatórios ambientais de empresas do setor de papel e celulose em nível internacional. (Tese de Doutorado). FEA/USP, Universidade de São Paulo, SP.

PAIVA, Paulo Roberto. (2003). Contabilidade ambiental: evidenciação dos gastos ambientais com transparência focada na prevenção. São Paulo: Atlas.

PLEVA, Eileen; GILBERTSON, Peter. (2006). Reconciling environmental disclosure with environmental exposure in an evolving regulatory climate. AIG Environmental. Disponível em: <http://www.erraonline.org/spring2003SEC.htm>. Acesso em: 15/out/2006.

PORTUGAL. Comissão de Normalização Contabilística. (2005). Directriz Contabilística NN. 29 - matérias ambientais.

REVISTA EXAME. (2006). Melhores e maiores - As 500 maiores empresas do Brasil. Edição anual. São Paulo: Ed. Abril, julho.

RIBEIRO, Maisa de Souza. (1992). Contabilidade e meio ambiente. (Dissertação de Mestrado). Faculdade de Economia, Administração e Contabilidade, FEA/USP, Universidade de São Paulo. 
Um estudo sobre o nível de aderência de companhias do segmento químico e petroquímico às normas e recomendações de disclosure ambiental internacionais, norte americanas e brasileiras Ângela Rosane Leal de Souza, Ernani Ott, Clóvis Antônio Kronbauer

. (1998). Custeio das atividades de natureza ambiental. (Tese de Doutorado). Universidade de São Paulo, São Paulo.

SEC - Securities and Exchange Commission. (1993). Staff Accounting Bulletin No. 92 SAB-92. Jun. Disponível em: <http://www.lexis-nexis.com/terms/general/>. Acesso em: 08/nov/2006.

. (2006). Regulation S-K. Disponível em: <http://www.law.uc.edu/CCL/regSK/index.html . Acesso em: 15/set/2006.

STANNY, Elizabeth. (1998). Effect of regulation on changes in disclosure of and reserved amounts for environmental liabilities. The Journal of Financial Statement Analysis, v. 3, n. 4, Summer.

SUTHERLAND, Donald. (2002). EPA reveals U.S. publicly traded corporations hide billions in environmental debt. Disponível em: <http://www.riskworld.com/ NEWS/02q2/nw02a096.htm>. Acesso em: 15/out/2006.

Data de Submissão: 30/09/2009

Data de Aceite: 21/12/2009 